\title{
Hyperglycemia affects global 5- methylcytosine and 5-hydroxymethylcytosine in blood genomic DNA through upregulation of SIRT6 and TETS
}

\author{
Er-Feng Yuan ${ }^{1,2+}$, Ying Yang ${ }^{1 \dagger}$, Lin Cheng ${ }^{3}$, Xujing Deng ${ }^{1}$, Shao-Min Chen ${ }^{1}$, Xin Zhou ${ }^{1}$ and Song-Mei Liu ${ }^{1 *}$ (D)
}

\begin{abstract}
Background: Accumulating evidence suggests that epigenetic changes play key roles in the pathogenesis of type 2 diabetes mellitus (T2DM). However, the dynamic regulation of 5-methylcytosine (5mC) and 5-hydroxymethylcytosine ( $5 \mathrm{hmC}$ ) in diabetic peripheral blood DNA remains to be elucidated.

Results: We collected fasting blood samples (104 patients and 108 healthy controls) and glucose-stimulated blood samples at different time points (11 patients and 5 healthy controls underwent oral glucose tolerance test (OGTT)), as well as blood samples from six couples of diabetic and control rats. A HPLC-MS/MS system was used for quantifying global $5 \mathrm{mC}$ and $5 \mathrm{hmC}$ in genomic DNA from white blood cells (WBCs), and qPCR was performed for detecting mRNA expression of SIRT6 and TETS. We found that global $5 \mathrm{mC}$ decreased, while global $5 \mathrm{hmC}$ increased in both patients and diabetic rats, with lower $5 \mathrm{mC}$ being a risk factor of T2DM (OR=0.524, 95\%Cl 0.402-0.683, $\left.p=1.64 \times 10^{-6}\right)$. The OGT data from patients showed that $5 \mathrm{mC}$ declined within $1 \mathrm{~h}$ and then returned to the fasting status at $2 \mathrm{~h}$, while $5 \mathrm{hmC}$ rose from $0.5 \mathrm{~h}$ to $3 \mathrm{~h}$ with increasing glucose. However, the similar patterns were not found in the controls. The mRNA expression of TET2, TET3, and SIRT6 was upregulated in patients ( $p=0.012, p=0.026$, and $p=0.035$, respectively). The similar results were observed in diabetic OGT and rats. Correlation analysis indicated that SIRT6 was positively correlated with TET2 in humans $(r=0.277, p<0.001)$ and rats $(r=0.942, p<0.001)$, in addition to a correlation between glucose and SIRT6 $(r=0.162, p=0.045)$ and TET2 $(r=0.174, p=0.036)$.
\end{abstract}

Conclusions: Hyperglycemia appeared to promote the mRNA expression of SIRT6 and TETs, which in turn might cause the dynamic changes of $5 \mathrm{mC}$ and $5 \mathrm{hmC}$ in WBCs from T2DM patients.

Keywords: 5-methylcytosine, 5-hydroxymethylcytosine, TET, SIRT6, Type 2 diabetes mellitus

\section{Background}

With an increasing incidence of obesity, diabetes has become a worldwide epidemic [1], which represents the sixth leading cause of disability, an overwhelming burden on individuals and global healthcare systems [2]. The International Diabetes Federation (IDF) reported that 425 million people were living with diabetes in

\footnotetext{
* Correspondence: smliu@whu.edu.cn

${ }^{\dagger}$ Er-Feng Yuan and Ying Yang contributed equally to this work.

'Department of Clinical Laboratory, Center for Gene Diagnosis \& Program of Clinical Laboratory, Zhongnan Hospital of Wuhan University, 169\# Donghu Road, Wuhan 430071, Hubei Province, China

Full list of author information is available at the end of the article
}

2017, with an estimated increase to 629 million by 2045 . About $>90 \%$ of patients have type 2 diabetes mellitus (T2DM) [2], which is a chronic, complex metabolic syndrome caused by the interaction of genetics, epigenetics, and environmental factors, including obesity, physical inactivity, and aging [3-5]. Relative insulin deficiency resulted from insulin resistance and impaired pancreatic $\beta$ cell function has been known as the etiology of T2DM $[2,6,7]$.

As a well-established epigenetic mark, DNA methylation most often occurs at the $5^{\prime}$-cytosines of $\mathrm{CpG}$ dinucleotides $[8,9]$. DNA methylation modification is a dynamic process in which methylation could be synthesized de

(c) The Author(s). 2019 Open Access This article is distributed under the terms of the Creative Commons Attribution 4.0 International License (http://creativecommons.org/licenses/by/4.0/), which permits unrestricted use, distribution, and reproduction in any medium, provided you give appropriate credit to the original author(s) and the source, provide a link to the Creative Commons license, and indicate if changes were made. The Creative Commons Public Domain Dedication waiver (http://creativecommons.org/publicdomain/zero/1.0/) applies to the data made available in this article, unless otherwise stated. 
novo, maintained, or removed. DNA methyltransferases (DNMTs) and DNA demethylases corporately maintain these processes with an intricate balance $[9,10]$. DNA demethylation can be catalyzed by ten-eleven translocation (TET) enzymes, which mediate the iterative oxidation of 5-methylcytosine $(5 \mathrm{mC})$ to 5-hydroxymethylcytosine (5hmC), 5-formylcytosine (5fC), and 5-carboxylcytosine $(5 \mathrm{caC})$ [11]. TET proteins are $\mathrm{Fe}(\mathrm{II})$ and alpha-ketoglutarate $(\alpha-K G)$-dependent enzymes, including TET1, TET2, and TET3 [11].

A link has been demonstrated between T2DM and epigenetic alterations [12-14]. Significant changes of TET2 expression and $5 \mathrm{hmC}$ abundance have been found in the umbilical veins of gestational diabetes mellitus (GDM) pregnancies [15]. Global $5 \mathrm{hmC}$ level in peripheral blood was elevated in poorly glucose controlled T2DM patients with glycated hemoglobin (HbA1c) $\geq 7 \%(n=25)$ compared to well-controlled T2DM patients with HbA1c $<7 \%$ $(n=19)$ and healthy individuals $(n=35)$ [16]. Recently, some new target genes with altered methylation and expression have been identified in pancreatic islets from T2DM by analyzing DNA methylation of 479,927 CpG sites and the transcriptome, indicating that the aberrant DNA methylation could perturb insulin and glucagon secretion [12]. Some blood-based and age-related DNA methylation biomarkers have also been identified in human islets and were found to be associated with insulin secretion and diabetes [4]. Data from retinal capillary cells and diabetic mouse models have shown that hyperglycemia leads to MMP-9 promoter hypomethylated and the activation of the demethylation machinery, resulting in its increased transcription. Silencing of TET2 could prevent hyperglycemia-induced increase in 5hmC and MMP-9 transcription [17]. A zebrafish study has further confirmed that hyperglycemia activates TETs to induce the demethylation of cytosines throughout the genome [18]. On the contrary, a recent study reported that hyperglycemic conditions had an adverse effect on the DNA 5-hydroxymethylome via the destabilization of TET2 [19].

SIRT6, a member of the sirtuin protein family, has been reported to mediate many important cellular processes, such as DNA repair, maintenance of genomic stability, anti-inflammation, gluconeogenesis, and insulin secretion [20-26].

Although studies have revealed altered DNA methylation patterns in pancreatic islets, adipose tissue, and skeletal muscle [5, 13, 27-30], it remains poorly understood that the dynamic regulation of $5 \mathrm{hmC}$ in peripheral blood-derived genomic DNA from T2DM patients, and whether blood glucose and the histone deacetylase SIRT6 are involved in this process. Therefore, we used a HPLC-MS/MS system for quantifying $5 \mathrm{mC}$ and $5 \mathrm{hmC}$ in genomic DNA from white blood cells (WBCs) in humans and rats and qPCR for detecting mRNA expression of SIRT6 and TETs to test the hypothesis that there might exist a link across SIRT6, TETs, and 5hmC in T2DM.

\section{Results}

\section{Clinical characteristics of the study subjects}

The clinical characteristics of 104 T2DM patients and 108 controls are shown in Table 1. There were no significant differences in age and gender between T2DM patients and controls $(p=0.301$ and $p=0.567$, respectively). As expected, patients had higher levels of fasting blood glucose $(p<0.001)$, TC $(p=0.028)$, TG $(p<0.001)$, and LDL-C $(p=0.014)$ and lower HDL-C $(p<0.001)$

Table 1 Clinical characteristics of the study subjects

\begin{tabular}{|c|c|c|c|}
\hline & T2DM patients $(n=104)$ & Controls $(n=108)$ & $p$ value \\
\hline Age (years) & $59.19 \pm 11.88$ & $57.59 \pm 10.60$ & $0.301^{a}$ \\
\hline Gender (male/female) & $58 / 46$ & $56 / 52$ & $0.567^{\mathrm{b}}$ \\
\hline Fasting blood glucose (mmol/L) & $8.58 \pm 0.49$ & $4.81 \pm 0.05$ & $<0.001^{a}$ \\
\hline Total cholesterol (TC, mmol/L) & $4.47 \pm 0.83$ & $4.25 \pm 0.52$ & $0.028^{\mathrm{a}}$ \\
\hline Triglyceride (TG, mmol/L) & $2.31 \pm 1.93$ & $1.09 \pm 0.32$ & $<0.001^{\mathrm{a}}$ \\
\hline High-density lipoprotein cholesterol (HDL-C, mmol/L) & $1.19 \pm 0.33$ & $1.53 \pm 0.30$ & $<0.001^{a}$ \\
\hline Low-density lipoprotein cholesterol (LDL-C, mmol/L) & $2.80 \pm 0.80$ & $2.57 \pm 0.40$ & $0.014^{\mathrm{a}}$ \\
\hline Insulin (uU/mL) & $10.12 \pm 6.85$ & & \\
\hline $\mathrm{HbA1c}(\%)$ & $8.56 \pm 2.22$ & & \\
\hline \multicolumn{4}{|l|}{ Vascular ultrasound } \\
\hline With macrovascular diseases & $68(65.4 \%)$ & & \\
\hline Without macrovascular diseases & $28(26.9 \%)$ & & \\
\hline N/A & 8 (7.7\%) & & \\
\hline
\end{tabular}

Data are presented as mean $\pm S D$

N/A not available

${ }^{\text {a }}$ Student's $t$ test

${ }^{b} x^{2}$ test 
than those of the controls. Pearson correlation analysis indicated that glucose was correlated with TG, TC, HDL-C, LDL-C and HbA1c (Additional file 1: Table S1). More than half of the patients $(n=68$, $65.4 \%$ ) also suffered from macrovascular diseases. The average of $\mathrm{HbA} 1 \mathrm{c}$ in patients was significantly above the reference range $(8.56 \%$ vs $<6.5 \%)$.

\section{Decreased $5 \mathrm{mC}$ and increased $5 \mathrm{hmC}$ in T2DM patients}

We first detected the global $5 \mathrm{mC}$ and $5 \mathrm{hmC}$ contents in 212 human DNA samples by HPLC-MS/MS in MRM mode. The $5 \mathrm{mC}$ contents in T2DM patients were significantly lower than those of the controls $(4.23 \pm 1.19 \%$ vs $4.95 \pm 1.24 \%, p<0.0001$; Fig. 1a), while the $5 \mathrm{hmC}$ contents were elevated $(0.0233 \pm 0.0169 \%$ vs $0.0194 \pm 0.0075 \%$, $p=0.036$; Fig. 1b). Significant correlations were found between the fasting blood glucose and $5 \mathrm{mC}(\beta=-0.218$, $p=0.006$; Fig. 1c) and 5hmC ( $\beta=0.224, p=0.006$; Fig. $1 \mathrm{~d})$ after controlling age and gender.

We further performed a multivariate logistic regression adjusted for age and gender to explore if the altered $5 \mathrm{mC}$ and $5 \mathrm{hmC}$ were the risk factors of T2DM. The results showed that lower $5 \mathrm{mC}$ was a risk factor of T2DM $\left(\mathrm{OR}=0.524,95 \% \mathrm{CI} 0.402-0.683, p=1.64 \times 10^{-6}\right)$; however, the $5 \mathrm{hmC}$ was not $(p=0.162)$.
Next, we evaluated the difference of $5 \mathrm{mC}$ and $5 \mathrm{hmC}$ between T2DM patients with or without macrovascular diseases and controls. The global $5 \mathrm{mC}$ level was the lowest in T2DM with macrovascular diseases, which is significantly lower than the controls $(p<0.0001)$ and those without macrovascular diseases $(p=0.010$, Fig. 1e). Interestingly, although the contents of $5 \mathrm{hmC}$ were elevated in T2DM with macrovascular diseases compared with controls $(p=0.020)$, the difference of $5 \mathrm{hmC}$ between T2DM with and without macrovascular diseases was not statistically significant (Fig. 1f).

\section{Dynamic $5 \mathrm{mC}$ and $5 \mathrm{hmC}$ mediated by glucose stimulation}

To further elucidate the role of glucose in the dynamic regulation of $5 \mathrm{mC}$ and $5 \mathrm{hmC}$, we performed an oral glucose tolerance test (OGTT) with a standard dose of $75 \mathrm{~g}$ glucose in 11 T2DM patients and 5 healthy controls. Peripheral blood samples were collected before glucose intake (fasting) and 30, 60, 120, and $180 \mathrm{~min}$ after glucose load. The contents of $5 \mathrm{mC}$ and $5 \mathrm{hmC}$ at five different time points were then analyzed with HPLC-MS/MS. As illustrated in Fig. 2, with increasing blood glucose (Fig. 2a), $5 \mathrm{mC}$ levels declined within $1 \mathrm{~h}$ and then went back to fasting status at the time point of $2 \mathrm{~h}$; the difference of $5 \mathrm{mC}$ is significant between fasting and $1 \mathrm{~h}(p=0.030)$ and $1 \mathrm{~h}$ and

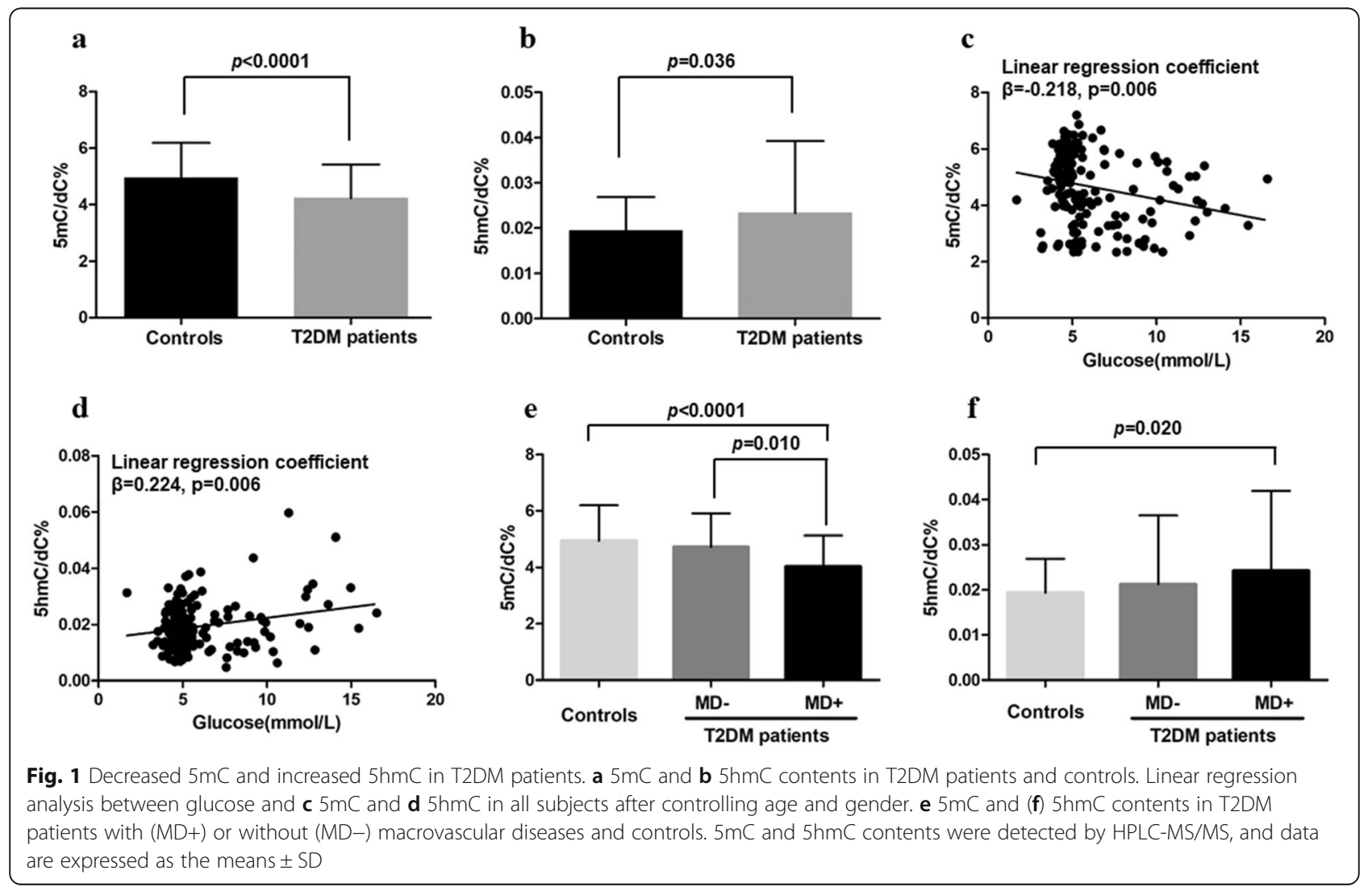



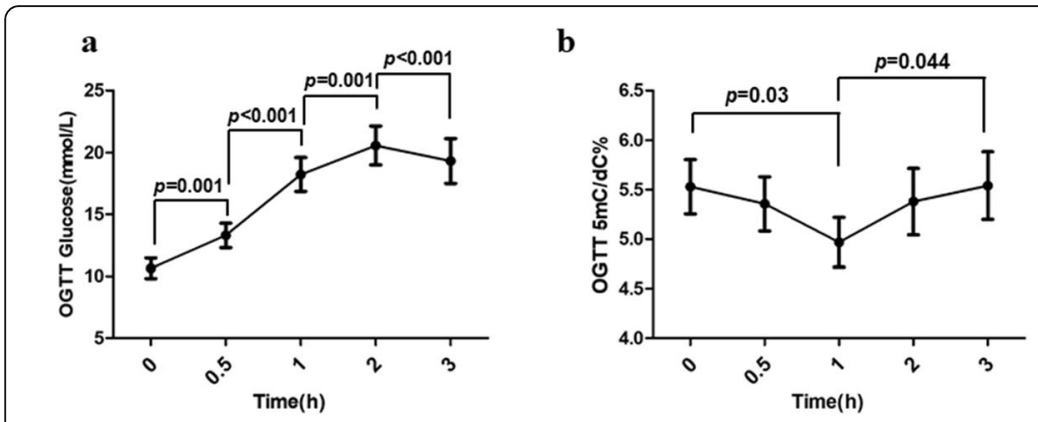

c
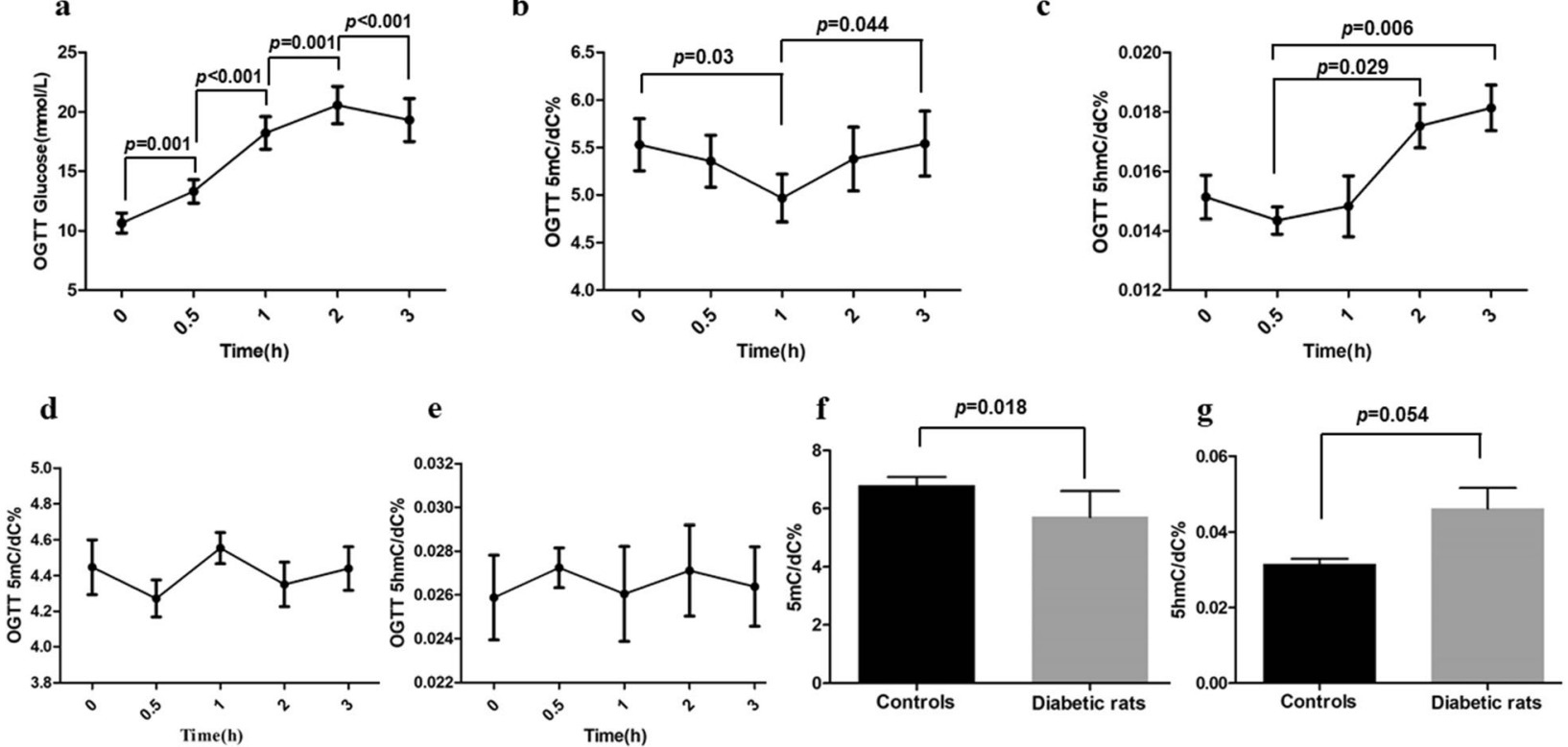

Fig. 2 Dynamic $5 \mathrm{mC}$ and $5 \mathrm{hmC}$ mediated by glucose stimulation. The levels of a glucose, $\mathbf{b} 5 \mathrm{mC}$, and $\mathbf{c} 5 \mathrm{hmC}$ at five different time points $(0,30$ $60,120$, and $180 \mathrm{~min})$ of OGTT from diabetes patients. The levels of $\mathbf{d} 5 \mathrm{mC}$ and $\mathbf{e} 5 \mathrm{hmC}$ at five different time points $(0,30,60,120$, and $180 \mathrm{~min})$ of OGTT from controls. $\mathbf{f} 5 \mathrm{mC}$ and $\mathbf{g} 5 \mathrm{hmC}$ contents in diabetic rats and controls. The contents of $5 \mathrm{mC}$ and $5 \mathrm{hmC}$ were detected by HPLC-MS/ $\mathrm{MS}$, and data are expressed as the means \pm SD

$3 \mathrm{~h}(p=0.044)$ in T2DM patients (Fig. 2b). In contrast, $5 \mathrm{hmC}$ levels rose from $0.5 \mathrm{~h}$ to $3 \mathrm{~h}$ with increasing blood glucose, the difference of $5 \mathrm{hmC}$ was significant between $0.5 \mathrm{~h}$ and $3 \mathrm{~h}(p=0.006$, Fig. $2 \mathrm{c})$ in T2DM patients. However, the similar patterns were not found in the controls. (Fig. 2d, e).

Similar to the results from human blood, global $5 \mathrm{mC}$ contents in diabetic rats were significantly decreased compared with controls ( $p=0.018$, Fig. $2 \mathrm{f}$ ), while $5 \mathrm{hmC}$ contents slightly increased, with marginal significance $(p=0.054$; Fig. $2 \mathrm{~g})$.

\section{Upregulation of TETs and SIRT6 in both T2DM patients and diabetic rats}

To explore the possible reasons for decreased $5 \mathrm{mC}$ and increased $5 \mathrm{hmC}$ in diabetes, we utilized qPCR to determine the mRNA expression of demethylation machinery genes and SIRT6 in diabetic patients and rats. Student's $t$ test showed that the mRNA expression levels of TET2, TET3, and SIRT6 were 1.47-, 1.17-, and 1.43-fold higher in T2DM patients than that in the controls $(p=0.012, p=0.026$, and $p=0.035$, respectively) (Fig. 3a). However, there was no significant difference in TET1 mRNA expression $(p=0.302)$ between T2DM patients and controls (Fig. 3a).

Except for TET1 (Fig. 3b), the mRNA expression of TET2, TET3, and SIRT6 significantly increased after glucose stimulation in 11 cases of T2DM patients participating OGTT. The paired Student $t$ test indicated that TET2 mRNA expression significantly elevated at $2 \mathrm{~h}$ when compared with fasting status and $0.5 \mathrm{~h}(2 \mathrm{~h}$ vs fasting, $p=$ $0.021 ; 2 \mathrm{~h}$ vs $0.5 \mathrm{~h}, p=0.027$; Fig. 3c); TET3 mRNA upregulated at $2 \mathrm{~h}$ and $3 \mathrm{~h}(2 \mathrm{~h}$ vs fasting, $p=0.005 ; 3 \mathrm{~h}$ vs fasting, $p=0.028$; Fig. 3d); and SIRT6 mRNA levels also showed an increase from $1 \mathrm{~h}$ after glucose intake $(1 \mathrm{~h}$ vs fasting, $p<0.001 ; 2 \mathrm{~h}$ vs fasting, $p=0.004 ; 3 \mathrm{~h}$ vs fasting, $p<0.001$; Fig. 3e).

To confirm the observations from human samples, we further test the mRNA levels of Tet1, Tet2, Tet 3 , and Sirt6 in blood samples from six couples of diabetic and control rats. Consistent with the results from T2DM patients, the mRNA expressions of Tet $2(p=0.045)$, Tet 3 $(p=0.045)$, and Sirt6 $(p=0.006)$ were significantly increased in diabetic rats compared with the controls (Fig. 3f). However, there was no significant difference in Tet1 mRNA levels between diabetic rats and the controls $(p=0.285)$ (Fig. 3f).

\section{Positive association of SIRT6 expression with TET2 and glucose}

Figure 4 presents the correlations across TETS, SIRT6, and glucose. In T2DM patients and controls, the Pearson correlation analysis revealed that glucose was positively associated with TET2 $(r=0.174, p=0.036)$ and SIRT6 ( $r=0.162, p=0.045$ ), while SIRT6 was positively associated with TET1 $(r=0.151, p=0.039)$ and TET2 $(r=0.277, p<0.001)$. The Spearman correlation analysis based on the results of OGTT showed that SIRT6 


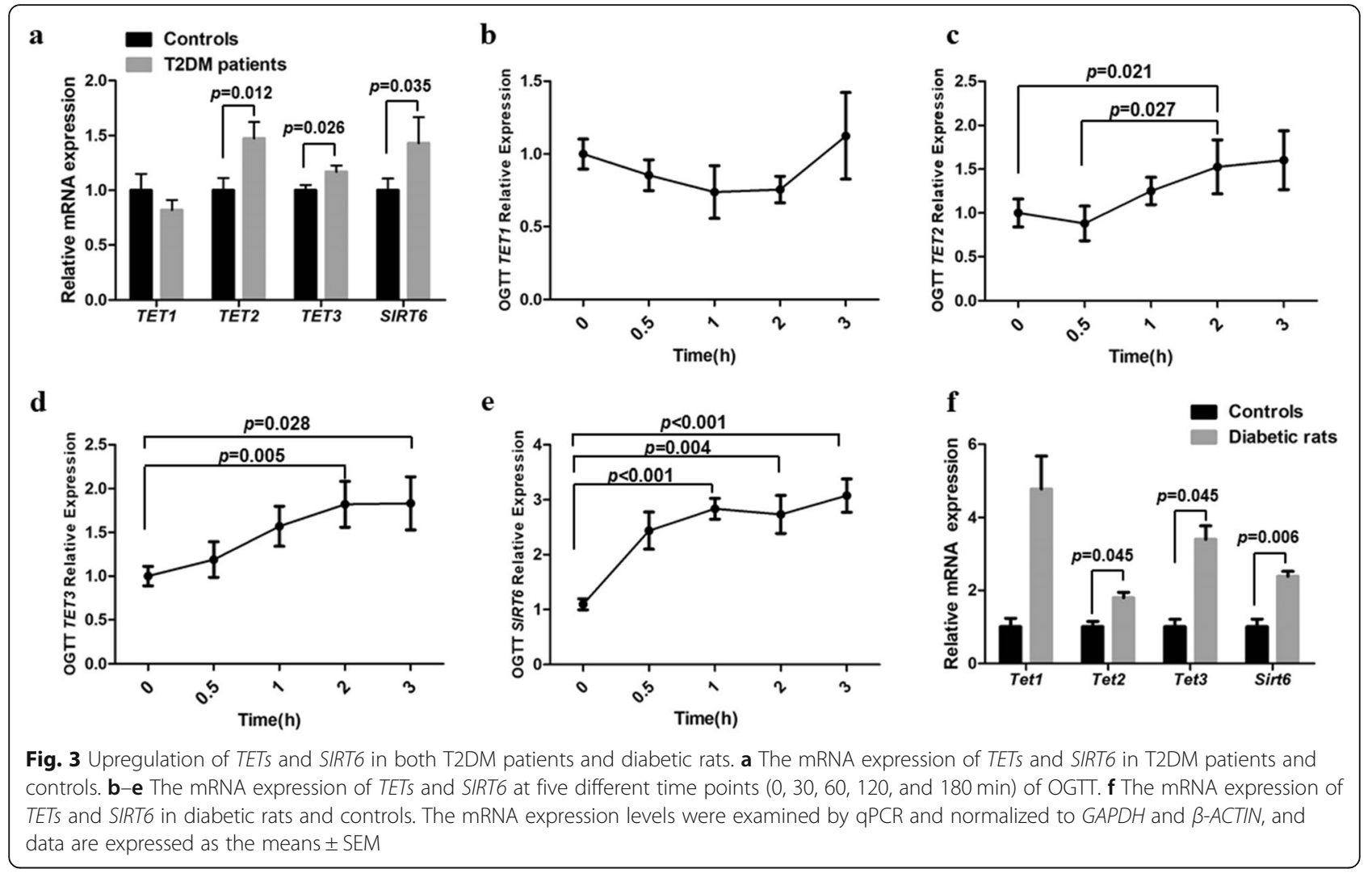

a
Human
OGTT
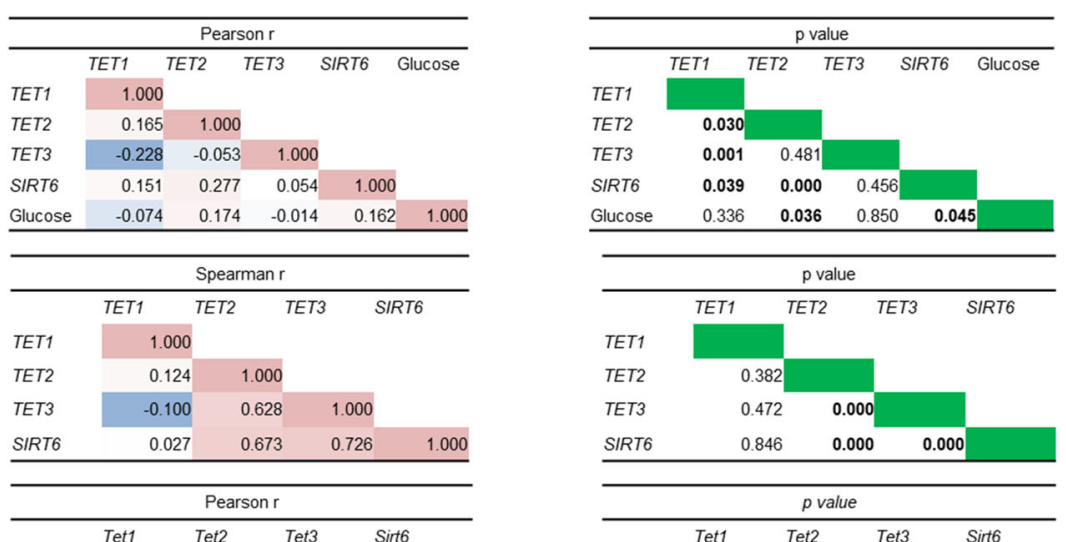

Rats

\begin{tabular}{|c|c|c|c|c|c|c|}
\hline \multicolumn{7}{|c|}{ Spearman $\mathrm{r}$} \\
\hline \multirow[b]{2}{*}{ TET1 } & TET1 & & & TET3 & & \\
\hline & \multicolumn{6}{|c|}{1.000} \\
\hline TET2 & & & \multicolumn{4}{|c|}{1.000} \\
\hline TET3 & & & 0.628 & \multicolumn{3}{|c|}{1.000} \\
\hline SIRT6 & & & 0.673 & & 726 & 1.000 \\
\hline \multicolumn{7}{|c|}{ Pearson $r$} \\
\hline
\end{tabular}

\begin{tabular}{l|lllll}
\hline Tet1 & 1.000 & & & \\
Tet2 & 0.971 & 1.000 & & \\
Tet3 & 0.428 & 0.805 & 1.000 & \\
\hline Sitt6 & 0.992 & 0.942 & 0.314 & 1.000 \\
\hline
\end{tabular}

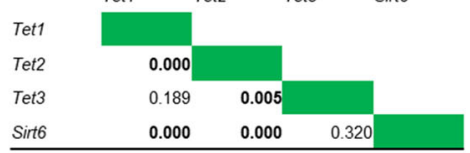

b

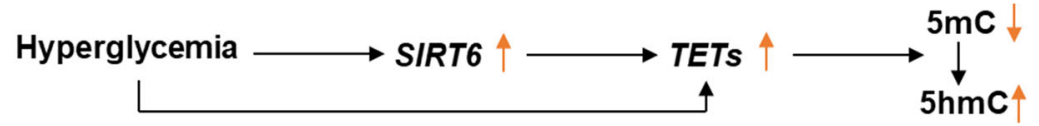

Fig. 4 The correlations cross SIRT6, TETS, glucose and the possible work model. a Correlation analysis between mRNA expression of SIRT6, TETS, and glucose in all human subjects (upper panel), OGTT (middle panel), and rats (lower panel). The correlation coefficients ( $r$ ) (left panel) and $p$ values (right panel) are shown. $\mathbf{b}$ The possible work model of DNA demethylation promoted by hyperglycemia via SIRT6 and TETS 
positively correlated with TET2 $(r=0.673, p<0.001)$ and TET3 $(r=0.726, p<0.001)$. In rats, the Pearson correlation analysis revealed that SIRT6 was positively associated with TET1 $(r=0.992, p<0.001)$ and TET2 $(r=0.942, p<0.001)$. Notably, the association of TET2 with SIRT6 existed in the studies of case - control, OGTT, and animals.

\section{Discussion}

The incidence and prevalence of T2DM have been on the rise globally. China definitely ranks first in terms of the absolute number of diabetic patients. The importance of epigenetics in T2DM has not been fully stated. Here, HPLC-MS/MS was used to measure global $5 \mathrm{mC}$ and $5 \mathrm{hmC}$ contents in T2DM blood samples. Our results demonstrated that $5 \mathrm{mC}$ decrease and $5 \mathrm{hmC}$ increase were mediated by glucose in T2DM patients and diabetic rats through upregulation of SIRT6 and TETs.

Indeed, the results would be more informative if we analyzed $5 \mathrm{mC}$ and $5 \mathrm{hmC}$ levels in different compositions of blood. However, isolation of cell subsets to detect $5 \mathrm{mC}$ and $5 \mathrm{hmC}$ needs $\sim 10 \mathrm{~mL}$ fresh peripheral blood as previously reported [31]. Here, we used a more clinically feasible amount of blood sample $(2 \mathrm{~mL})$ to perform experiments, which is not enough to isolate different composition. To exclude the differences between diabetic and non-diabetic individuals is the effect of differing blood cell proportions, we compared the differences of WBCs, neutrophils, lymphocytes, and monocytes between T2DM patients and controls. The results showed that there were no significant differences in different blood cells between these two groups (Additional file 1: Figure S1).

Despite some reports suggesting alterations in $5 \mathrm{mC}$ in human islets from T2DM [4, 12, 32], 5hmC in umbilical vein tissues from GDM by genome-wide profiling [15], as well as controversial changes in $5 \mathrm{mC}$ and $5 \mathrm{hmC}$ in peripheral blood from diabetic patients in two independent studies with commercial kits or HPLC-MS/MS $[16,19]$. A study with human peripheral blood in Colombia by Pinzon-Cortes JA. et al. reported that both $5 \mathrm{mC}$ and $5 \mathrm{hmC}$ were increased in poorly glucose controlled diabetic patients with HbA1c > 7\% [16], while another recent study found that $5 \mathrm{hmC}$ in peripheral blood monocytes from diabetic patients $(n=18)$ was lower than the healthy controls $(n=15)$ [19]. Consistent with a previous report [16], our findings also suggested that $5 \mathrm{hmC}$ in WBCs fromT2DM patients statistically increased independent of macrovascular events, and demethylation machinery genes TET2 and TET3 concordantly upregulated in patients and animals, which might attribute to the elevation of $5 \mathrm{hmC}$. With this data, we provided further evidence of the higher content of $5 \mathrm{hmC}$ in T2DM. Because $5 \mathrm{mC}$ is required as a substrate for oxidation to generate $5 \mathrm{hmC}$ by TETs, the increase in $5 \mathrm{hmC}$ could be partially responsible for the reduced $5 \mathrm{mC}$. In line with a recent study [19], our patients without macrovascular complications had the similar $5 \mathrm{mC}$ levels to the controls.

Given the importance of SIRT6 in DNA methylation, insulin secretion, as well as glucose and fat metabolism [6, 20-26, 33], we tested mRNA expression of SIRT6 and found that SIRT6 elevated significantly in both patients and rats. Similarly, loss of SIRT6 could induce global hypomethylation, hypoglycemia, and increased fat deposition in hepatocellular carcinoma [33]. Sirt6 knockdown in MIN6 beta cells led to a significant decrease in glucose-stimulated insulin secretion [6] and an increase in palmitate-induced pancreatic $\beta$-cell dysfunction and apoptosis [20]. Interestingly, a recent in vivo pharmacological study has documented that Sirt6 inhibition improved glucose tolerance in the T2DM mouse model, associated with reduced insulin, triglycerides, and cholesterol levels in plasma, suggesting that SIRT6 inhibitor might be a strategy for glycemic control in T2DM [34]. In contrast, embryonic stem cells (ESCs) derived from Sirt6 knockout mice showed an upregulation of Tet enzymes and elevated production of $5 \mathrm{hmC}$ [35].

Clearly, hyperglycemia is known as a distinct pathological feature of T2DM; intensive control of glucose would be beneficial for preventing the progress of T2DM [8]. Thus, we investigated the correlations between glucose and $5 \mathrm{mC}$ and $5 \mathrm{hmC}$. To our knowledge, the current work is the first study to reveal the role of glucose in the regulation of dynamic DNA methylation in the human body. Our findings in general populations suggested glucose negatively correlated with $5 \mathrm{mC}$ and were positively associated with $5 \mathrm{hmC}$. Furthermore, the dynamic changes of $5 \mathrm{mC}$ and $5 \mathrm{hmC}$ contents after oral glucose were in line with what we found in T2DM patients and diabetic rats exposed to prolonged hyperglycemia, making the altered DNA methylation pattern in blood from T2DM patients likely to be caused of persistent hyperglycemia.

To further illustrate how high glucose might lead to DNA methylation alterations, we tested the mRNA expression of SIRT6 and TETs in all study subjects and rats. Our results suggested that SIRT6 positively correlated with TET2 in humans and rats, and there existed a link between glucose and SIRT6 and TET2. A possible model in T2DM patients might work as Fig. 4b, in which hyperglycemia could promote DNA demethylation via upregulation of SIRT6 and TET2.

We realized there were several limitations in the current study. Firstly, the sample size of the OGTT was small. Secondly, using peripheral blood did not allow us to detect the differences of $5 \mathrm{mC}$ and $5 \mathrm{hmC}$ between diabetic and non-diabetic individuals in different blood cell components. Although this study only detected the mRNA expression of interest genes due to the limited blood 
volume, to our knowledge, we are the first to report the alterations of $5 \mathrm{mC}$, $5 \mathrm{hmC}, T E T s$, and SIRT6 at different time points after oral glucose uptake in diabetic patients.

\section{Conclusion}

In summary, our results reflected the dynamic DNA methylation influenced by glucose stimulation in human blood, suggesting that epigenetic alterations including DNA methylation emerged as an important determinant of diabetes, which further verified our hypothesis and highlighted that SIRT6 might be a potential target for glucose control.

\section{Methods}

\section{Human blood samples}

Our study was approved by the Medical Ethics Committee of Zhongnan Hospital of Wuhan University (approval number 2014039), and written informed consents were obtained from each participant. A 1:1 matched case-control samples were collected $(\mathrm{T} 2 \mathrm{DM}$ patients = 104, controls $=108$ ) from Zhongnan Hospital of Wuhan University. Patients were diagnosed as T2DM according to the Standards of Medical Care in Diabetes 2012 of the American Diabetes Association (ADA). The age- and gender-matched controls were randomly enrolled from healthy individuals who were free of endocrine diseases, cardiovascular diseases, and cancers. Another 11 T2DM patients and five controls participating in OGTT were also enrolled for further investigation of the dynamic regulation of $5 \mathrm{mC}$ and $5 \mathrm{hmC}$ after glucose stimulation. Biochemical parameters were determined by Beckman AU5800 chemistry analyzer with Beckman commercial kits in the clinical laboratory, including fasting blood glucose, triglycerides (TG), total cholesterol (TC), high-density lipoprotein cholesterol (HDL-C), and low-density lipoprotein cholesterol (LDL-C). Blood HbA1c was detected by ADAMS HA-8160 high-performance liquid chromatography. Serum insulin was determined by Abbott i4000SR Immunology Analyzer with i2000 commercial kits. Artery ultrasound was utilized to test the presence of atherosclerotic plaque, an indicator for macrovascular diseases.

\section{Diabetic animal model establishment}

Male Wistar rats (6-8 weeks old; $175-200 \mathrm{~g}$ ) were purchased from the Hubei Provincial Center for Disease Control and Prevention. Diabetic rats were established according to our previous protocol [36]. Rats that had blood glucose levels higher than $11.6 \mathrm{mmol} / \mathrm{L}$ were regarded as diabetic rats. Six diabetic and six non-diabetic rats were used for this study. All animal procedures were performed in accordance with the guidelines of the Institutional Animal Care and Use Committee of Wuhan University.

\section{DNA extraction and enzymatic digestion}

Genomic DNA was extracted from peripheral WBCs. DNA digestion was performed according to the previous study with minor modification [37]. Briefly, $~ 1.5 \mu \mathrm{g}$ DNA

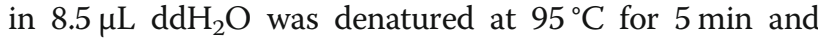
chilled on ice for $2 \mathrm{~min}$. Then, $1 \mu \mathrm{L}$ of $\mathrm{S} 1$ nuclease buffer and 100 units $(0.5 \mu \mathrm{L})$ S1 nuclease (Thermo Scientific, Waltham, MA) were added and incubated at $37^{\circ} \mathrm{C}$ for $4 \mathrm{~h}$. Next, $24.5 \mu \mathrm{L} \mathrm{H}_{2} \mathrm{O}, 4 \mu \mathrm{L}$ alkaline phosphatase buffer, 15 units $(0.5 \mu \mathrm{L})$ of alkaline phosphatase (TaKaRa, Dalian, China), and 0.001 units $(1 \mu \mathrm{L})$ of venom phosphodiesterase I were added to the solution (Sigma, St. Louis, MO). The mixture $(40 \mu \mathrm{L})$ was incubated for another $2 \mathrm{~h}$ at $37^{\circ} \mathrm{C}$. The resulting solution was extracted with an equal volume of chloroform twice and followed by an ultrafiltration with YM-10 column (Microcon, Shanghai, China). The flow-through was monitored by HPLC-MS/ MS to quantify the content of $5 \mathrm{mC}$ and $5 \mathrm{hmC}$.

\section{Measurement of global $5 \mathrm{mC}$ and $5 \mathrm{hmC}$}

Analysis of $5 \mathrm{mC}$ and $5 \mathrm{hmC}$ was operated on an Agilent HPLC-MS/MS 6410 Triple Quad mass spectrometer (Agilent, CA) with an electrospray ionization source under positive ion mode. An ultimate XB-C18 column $(150 \mathrm{~mm} \times$ $2.1 \mathrm{~mm}$ i.d., $3 \mu \mathrm{m}$, Weltech Co., Ltd., Wuhan, China) was used for the separation of target analytes. The parameters for mass spectrometry detection were as follows: gas flow, $10 \mathrm{~L} / \mathrm{min}$; nebulizer pressure, $40 \mathrm{psi}$; drying gas temperature, $320^{\circ} \mathrm{C}$; and capillary voltage, $3500 \mathrm{~V}$. The product ions derived from the precursor ions were monitored by multiple reaction monitoring mode (MRM) using the mass transitions (precursor ions $\rightarrow$ product ions) of 2'-deoxyadenosine (dA) $\quad(252.4 \rightarrow 136.2)$, thymidine $(\mathrm{T}) \quad(243.3 \rightarrow 127.2)$, 2'-deoxyguanosine $(\mathrm{dG})(268.4 \rightarrow 152.4), 2$ '-deoxycytidine $(\mathrm{dC}) \quad(228.4 \rightarrow 112.2), 5 \mathrm{mC} \quad(242.0 \rightarrow 126.0)$, and $5 \mathrm{hmC}$ $(258.0 \rightarrow 142.0)$.

The linearity was examined using $2.5 \mathrm{pmol} \mathrm{dC}$ standard supplemented with $5 \mathrm{mC}$ and $5 \mathrm{hmC}$ at different amounts ranging from $0.05 \mathrm{pmol}$ to $0.5 \mathrm{pmol}$ and $0 \mathrm{pmol}$ to $0.005 \mathrm{pmol}$, respectively. The calibration curves were plotted with the expected molar ratio of $5 \mathrm{mC} / \mathrm{dC}$ or $5 \mathrm{hmC} / \mathrm{dC}$ vs the observed molar ratio of $5 \mathrm{mC} / \mathrm{dC}$ or $5 \mathrm{hmC} / \mathrm{dC}$ based on data obtained from triplicate measurements. The results showed linearity within the range of $2-20 \%$ (molar ratio of $5 \mathrm{mC} / \mathrm{dC}$ ) and $0-0.2 \%$ (molar ratio of $5 \mathrm{hmC} / \mathrm{dC}$ ) with a coefficient of determination $\left(R^{2}\right)$ higher than 0.99 .

\section{Quantification of mRNA expression by qPCR}

To assess the mRNA expression of human TET1, TET2, TET3, and SIRT6, and rat Tet1, Tet2, Tet3, Sirt6, total RNA was extracted from the peripheral WBCs using TRIzol reagent (Invitrogen, Carlsbad, CA), then, cDNA synthesis was performed with DNase treatment and 
reverse transcription (TOYOBO, Osaka, Japan). The mRNA expression of target genes and the reference genes GAPDH and $\beta$-ACTIN were measured by quantitative qPCR using CFX96 Touch TM Real-Time PCR System with iTaq TM Universal SYBR Green Supermix (Bio-Rad, Hercules, CA). Intron-spanning primer sequences are listed in Additional file 1: Table S2, and the results are displayed as the means \pm SEM.

\section{Statistical analysis}

We performed all the statistical analyses using SPSS 21.0 software. A normality test was used to explore the data distribution. Student $t$ test was used to evaluate the differences for normally distributed data between two groups. A paired Student $t$ test was used to compare the differences between different time points of OGTT. A logistic regression model adjusted for age and gender was performed to explore if the altered $5 \mathrm{mC}$ and $5 \mathrm{hmC}$ were the risk factors of T2DM. A linear regression model adjusted for age and gender was used to explore the correlations between glucose and $5 \mathrm{mC}$ and $5 \mathrm{hmC}$. Pearson correlation coefficients for normal distributed data and Spearman correlation coefficients for non-normal distributed data were used for evaluation of the correlations between gene expression and $5 \mathrm{mC}$ and 5hmC. $p<0.05$ was considered to be statistically significant.

\section{Additional file}

Additional file 1: Figure S1. The comparison of white blood cells (WBC), neutrophil (NEUT), lymphocyte (LYMPH) and monocyte (MONO) in T2DM patients and controls. Data are expressed as the means \pm SD. Table S1. Correlations between glucose and biochemical parameters. Table S2. Primers used for qPCR. (DOCX 64 kb)

\section{Abbreviations}

5hmC: 5-hydroxymethylcytosine; 5mC: 5-hethylcytosine; HbA1c: Glycated hemoglobin; HDL-C: High-density lipoprotein cholesterol; HPLC-MS/ MS: High-performance liquid chromatography-mass spectrometry; LDLC: Low density lipoprotein cholesterol; OGTT: Oral glucose tolerance test; SIRT6: Sirtuin 6; TC: Total cholesterol; TETs: Ten-eleven translocation proteins; TG: Triglycerides; WBC: White blood cell

\section{Acknowledgements}

We thank the financial support from the National Natural Science Foundation of China and Health Commission of Hubei Province Scientific Research Project. We also appreciate professor Wei Zhang and Chang Zeng (Department of Preventive Medicine, Northwestern University Feinberg School of Medicine, USA) for help critical statistical analysis and manuscript review.

\section{Funding}

SML was supported by the National Natural Science Foundation of China $(81772276,81472023,91753201)$ and Health Commission of Hubei Province Scientific Research Project (WJ2019H005).

\section{Availability of data and materials}

The data used and/or analyzed during the current study are available from the corresponding author on reasonable request.

\section{Authors' contributions}

EFY and SML designed the research. EFY and YY conducted the GPCR and diabetic rat model establishment. XJD and SMC collected the blood samples and clinical information. EFY and LC detected the $5 \mathrm{mC}$ and $5 \mathrm{hmC}$ contents. $E F Y, Y Y, X Z$, and $S M L$ prepared the initial manuscript draft. $Y Y$ and $S M L$ edited and revised the subsequent drafts. SML had primary responsibility for the final content. All authors read and approved the final manuscript.

\section{Ethics approval and consent to participate}

This study was approved by the Medical Ethics Committee of Zhongnan Hospital of Wuhan University (approval number 2014039). and written informed consents were obtained from each participant.

\section{Consent for publication}

Not applicable

\section{Competing interests}

The authors declare that they have no competing interests

\section{Publisher's Note}

Springer Nature remains neutral with regard to jurisdictional claims in published maps and institutional affiliations.

\section{Author details}

'Department of Clinical Laboratory, Center for Gene Diagnosis \& Program of Clinical Laboratory, Zhongnan Hospital of Wuhan University, 169\# Donghu Road, Wuhan 430071, Hubei Province, China. ${ }^{2}$ Department of Clinical Laboratory, The Third Affiliated Hospital of Zhengzhou University, Zhengzhou 450052, Henan Province, China. ${ }^{3}$ Key Laboratory of Combinatorial Biosynthesis and Drug Discovery, Ministry of Education, School of Pharmaceutical Sciences, Wuhan University, Wuhan 430071, Hubei Province, China.

Received: 14 October 2018 Accepted: 31 March 2019

Published online: 15 April 2019

\section{References}

1. The L. Obesity and diabetes in 2017: a new year. Lancet. 2017;389(10064):1.

2. Chatterjee S, Khunti K, Davies MJ. Type 2 diabetes. Lancet. 2017; 389(10085):2239-51.

3. Kelstrup L, Hjort L, Houshmand-Oeregaard A, Clausen TD, Hansen NS, Broholm C, et al. Gene expression and DNA methylation of PPARGC1A in muscle and adipose tissue from adult offspring of women with diabetes in pregnancy. Diabetes. 2016;65(10):2900-10.

4. Bacos K, Gillberg L, Volkov P, Olsson AH, Hansen T, Pedersen O, et al. Blood-based biomarkers of age-associated epigenetic changes in human islets associate with insulin secretion and diabetes. Nat Commun. 2016;7:11089.

5. Ronn T, Ling C. DNA methylation as a diagnostic and therapeutic target in the battle against type 2 diabetes. Epigenomics. 2015;7(3):451-60.

6. Xiong X, Wang G, Tao R, Wu P, Kono T, Li K, et al. Sirtuin 6 regulates glucose-stimulated insulin secretion in mouse pancreatic beta cells. Diabetologia. 2016;59(1):151-60.

7. Li ZY, Song J, Zheng SL, Fan MB, Guan YF, Qu Y, et al. Adipocyte Metrnl antagonizes insulin resistance through PPARgamma signaling. Diabetes. 2015;64(12):4011-22

8. Reddy MA, Zhang E, Natarajan R. Epigenetic mechanisms in diabetic complications and metabolic memory. Diabetologia. 2015;58(3):443-55.

9. Siedlecki P, Zielenkiewicz P. Mammalian DNA methyltransferases. Acta Biochim Pol. 2006;53(2):245-56.

10. Chen Z, Li S, Subramaniam S, Shyy JY, Chien S. Epigenetic regulation: a new frontier for biomedical engineers. Annu Rev Biomed Eng. 2017;19:195-219.

11. Ito S, Shen L, Dai Q, Wu SC, Collins LB, Swenberg JA, et al. Tet proteins can convert 5-methylcytosine to 5-formylcytosine and 5-carboxylcytosine. Science. 2011;333(6047):1300-3.

12. Dayeh T, Volkov P, Salo S, Hall E, Nilsson E, Olsson AH, et al. Genome-wide DNA methylation analysis of human pancreatic islets from type 2 diabetic and non-diabetic donors identifies candidate genes that influence insulin secretion. PLoS Genet. 2014;10(3):e1004160.

13. Yang BT, Dayeh TA, Kirkpatrick CL, Taneera J, Kumar R, Groop L, et al. Insulin promoter DNA methylation correlates negatively with insulin gene 
expression and positively with $\mathrm{HbA}(1 \mathrm{c})$ levels in human pancreatic islets. Diabetologia. 2011;54(2):360-7.

14. Ling C, Groop L. Epigenetics: a molecular link between environmental factors and type 2 diabetes. Diabetes. 2009;58(12):2718-25.

15. Sun M, Song MM, Wei B, Gao Q, Li L, Yao B, et al. 5-Hydroxymethylcytosinemediated alteration of transposon activity associated with the exposure to adverse in utero environments in human. Hum Mol Genet. 2016;25(11):2208-19.

16. Pinzon-Cortes JA, Perna-Chaux A, Rojas-Villamizar NS, Diaz-Basabe A, Polania-Villanueva DC, Jacome MF, et al. Effect of diabetes status and hyperglycemia on global DNA methylation and hydroxymethylation. Endocr Connect. 2017;6(8):708-25.

17. Kowluru RA, Shan Y, Mishra M. Dynamic DNA methylation of matrix metalloproteinase-9 in the development of diabetic retinopathy. Lab Invest. 2016;96(10):1040-9.

18. Dhliwayo N, Sarras MP Jr, Luczkowski E, Mason SM, Intine RV. Parp inhibition prevents ten-eleven translocase enzyme activation and hyperglycemiainduced DNA demethylation. Diabetes. 2014;63(9):3069-76.

19. Wu D, Hu D, Chen H, Shi G, Fetahu IS, Wu F, et al. Glucose-regulated phosphorylation of TET2 by AMPK reveals a pathway linking diabetes to cancer. Nature. 2018;559(7715):637-41.

20. Xiong X, Sun X, Wang Q, Qian X, Zhang Y, Pan X, et al. SIRT6 protects against palmitate-induced pancreatic beta-cell dysfunction and apoptosis. J Endocrinol. 2016;231(2):159-65.

21. Sahin K, Yilmaz S, Gozukirmizi N. Changes in human sirtuin 6 gene promoter methylation during aging. Biomed Rep. 2014;2(4):574-8,

22. Cardus A, Uryga AK, Walters G, Erusalimsky JD. SIRT6 protects human endothelial cells from DNA damage, telomere dysfunction, and senescence. Cardiovasc Res. 2013;97(3):571-9.

23. Dong XC. Sirtuin biology and relevance to diabetes treatment. Diabetes Manag. 2012;2(3):243-57.

24. Mao Z, Hine C, Tian X, Van Meter M, Au M, Vaidya A, et al. SIRT6 promotes DNA repair under stress by activating PARP1. Science. 2011;332(6036):1443-6.

25. Xiao C, Kim HS, Lahusen T, Wang RH, Xu X, Gavrilova O, et al. SIRT6 deficiency results in severe hypoglycemia by enhancing both basal and insulin-stimulated glucose uptake in mice. J Biol Chem. 2010;285(47):36776-84.

26. Kanfi Y, Peshti V, Gil R, Naiman S, Nahum L, Levin E, et al. SIRT6 protects against pathological damage caused by diet-induced obesity. Aging Cell. 2010;9(2):162-73.

27. Marco A, Kisliouk T, Tabachnik T, Weller A, Meiri N. DNA CpG methylation (5-methylcytosine) and its derivative (5hydroxymethylcytosine) alter histone posttranslational modifications at the Pomc promoter, affecting the impact of perinatal diet on leanness and obesity of the offspring. Diabetes. 2016;65(8):2258-67.

28. Yang BT, Dayeh TA, Volkov PA, Kirkpatrick CL, Malmgren S, Jing X, et al. Increased DNA methylation and decreased expression of PDX-1 in pancreatic islets from patients with type 2 diabetes. Mol Endocrinol. 2012;26(7):1203-12.

29. Ribel-Madsen R, Fraga MF, Jacobsen S, Bork-Jensen J, Lara E, Calvanese $V$, et al. Genome-wide analysis of DNA methylation differences in muscle and fat from monozygotic twins discordant for type 2 diabetes. PLoS One. 2012;7(12):e51302.

30. Nitert MD, Dayeh T, Volkov P, Elgzyri T, Hall E, Nilsson E, et al. Impact of an exercise intervention on DNA methylation in skeletal muscle from first-degree relatives of patients with type 2 diabetes. Diabetes. 2012;61(12):3322-32.

31. Deng Q, Huang W, Peng C, Gao J, Li Z, Qiu X, et al. Genomic 5-mC contents in peripheral blood leukocytes were independent protective factors for coronary artery disease with a specific profile in different leukocyte subtypes. Clin Epigenetics. 2018;10:9.

32. Volkmar M, Dedeurwaerder S, Cunha DA, Ndlovu MN, Defrance M, Deplus R, et al. DNA methylation profiling identifies epigenetic dysregulation in pancreatic islets from type 2 diabetic patients. EMBO J. 2012;31(6):1405-26.

33. Marquardt JU, Fischer K, Baus K, Kashyap A, Ma S, Krupp M, et al. Sirtuin-6-dependent genetic and epigenetic alterations are associated with poor clinical outcome in hepatocellular carcinoma patients. Hepatology. 2013;58(3):1054-64.

34. Sociali G, Magnone M, Ravera S, Damonte P, Vigliarolo T, Von Holtey M, et al. Pharmacological Sirt6 inhibition improves glucose tolerance in a type 2 diabetes mouse model. FASEB J. 2017;31(7):3138-49.

35. Etchegaray JP, Chavez L, Huang Y, Ross KN, Choi J, Martinez-Pastor B, et al. The histone deacetylase SIRT6 controls embryonic stem cell fate via TET-mediated production of 5-hydroxymethylcytosine. Nat Cell Biol. 2015;17(5):545-57

36. Shen F, Huang W, Huang JT, Xiong J, Yang Y, Wu K, et al. Decreased N(6)methyladenosine in peripheral blood RNA from diabetic patients is associated with FTO expression rather than ALKBH5. J Clin Endocrinol Metab. 2015;100(1):E148-54.

37. Chen ML, Shen F, Huang W, Qi JH, Wang Y, Feng YQ, et al. Quantification of 5-methylcytosine and 5-hydroxymethylcytosine in genomic DNA from hepatocellular carcinoma tissues by capillary hydrophilic-interaction liquid chromatography/quadrupole TOF mass spectrometry. Clin Chem. 2013;59(5):824-32.
Ready to submit your research? Choose BMC and benefit from:

- fast, convenient online submission

- thorough peer review by experienced researchers in your field

- rapid publication on acceptance

- support for research data, including large and complex data types

- gold Open Access which fosters wider collaboration and increased citations

- maximum visibility for your research: over $100 \mathrm{M}$ website views per year

At $\mathrm{BMC}$, research is always in progress.

Learn more biomedcentral.com/submissions 